\title{
Role of Calcium, Glutamate Neurotransmission, and Nitric Oxide in Spreading Acidification and Depression in the Cerebellar Cortex
}

\author{
Gang Chen, Robert L. Dunbar, Wangcai Gao, and Timothy J. Ebner \\ Department of Neuroscience, University of Minnesota, Minneapolis, Minnesota 55455
}

This study investigated the mechanisms underlying the recently reported fast spreading acidification and transient depression in the cerebellar cortex in vivo. Spreading acidification was evoked by surface stimulation in the rat and mouse cerebellar cortex stained with the $\mathrm{pH}$-sensitive dye neutral red and monitored using epifluorescent imaging. The probability of evoking spreading acidification was dependent on stimulation parameters; greater frequency and/or greater amplitude were more effective. Although activation of the parallel fibers defined the geometry of the spread, their activation alone was not sufficient, because blocking synaptic transmission with low $\mathrm{Ca}^{2+}$ prevented spreading acidification. Increased postsynaptic excitability was also a major factor. Application of either AMPA or metabotropic glutamate receptor antagonists reduced the likelihood of evoking spreading acidification, but stronger stimulation intensities were still effective. Conversely, superfusion with GABA receptor antagonists decreased the threshold for evoking spreading acidification. Blocking nitric oxide synthase

Several types of propagating waves of activity occur in the CNS. Classic spreading depression (SD) of Leao is characterized by a slowly propagating wave of neuronal and glial depolarization with large shifts in the ionic gradients that leads to a profound loss of spontaneous and evoked neuronal activity (Leao, 1944; Ochs, 1962; Lauritzen and Nicholson, 1988). Astrocytic gap junctions have been implicated as a possible route for SD propagation (Largo et al., 1997; Martins-Ferreira et al., 2000). Calcium waves in neuronal-glial cultures and in vitro preparations have been shown to propagate either via glial coupling by gap junctions or an extracellular messenger (Yoon et al., 1996; Newman and Zahs, 1997; Guthrie et al., 1999). Both pathophysiological processes and signaling mechanisms have been ascribed to these propagated activities (Lauritzen and Nicholson, 1988; Cornell-Bell et al., 1990; Somjen et al., 1992; Newman and Zahs 1997).

Recently we described a novel form of propagated activity in the rat cerebellar cortex in vivo based on optical imaging of $\mathrm{pH}$ changes using neutral red (Chen et al., 1999a). Surface stimulation was shown to evoke a "parallel fiber-like" beam of activity (Chen et al., 1998, 1999a; Hanson et al., 2000). In some animals, this beam of optical activity spread anteriorly and posteriorly across the folium, a phenomenon referred to as spreading acidi-

Received May 23, 2001; revised Sept. 20, 2001; accepted Oct. 1, 2001.

This work was supported by National Institutes of Health Grant P01-NS31318. We thank Yanhua Pan for animal preparation, Mike L. McPhee for expert graphics, and Brigitte Welter and Linda King for help in preparing this manuscript.

Correspondence should be addressed to Dr. Timothy J. Ebner, Department of Neuroscience, University of Minnesota, Lions Research Building, 2001 Sixth Street Southeast, 421, Minneapolis, MN 55455. E-mail: ebner001@umn.edu.

Copyright (C) 2001 Society for Neuroscience $0270-6474 / 01 / 219877-11 \$ 15.00 / 0$
(NOS) increased the threshold for spreading acidification, and nitric oxide donors lowered the threshold. However, spreading acidification could be evoked in neuronal NOS-deficient mice $\left(\mathrm{B} 6 ; 129 \mathrm{~S}-\mathrm{Nos}^{\mathrm{tm} 1 \mathrm{plh}}\right)$. The depression in cortical excitability that accompanies spreading acidification occurred in the presence of AMPA and metabotropic glutamate receptor antagonists and NOS inhibitors. These findings suggest that spreading acidification is dependent on extracellular $\mathrm{Ca}^{2+}$ and glutamate neurotransmission with a contribution from both AMPA and metabotropic glutamate receptors and is modulated by nitric oxide. Therefore, spreading acidification involves both presynaptic and postsynaptic mechanisms. We hypothesize that a regenerative process, i.e., a nonpassive process, is operative that uses the cortical architecture to account for the high speed of propagation.

Key words: cerebellum; calcium; glutamate; nitric oxide; optical imaging; neutral red; rat; transgenic mouse; spreading depression; calcium waves

fication. Transient but powerful depression of both presynaptic and postsynaptic activity accompanies spreading acidification. With an average propagation speed of $450 \mu \mathrm{m} / \mathrm{sec}$ and peak speeds as high as $1100 \mu \mathrm{m} / \mathrm{sec}$, spreading acidification travels much faster than other known forms of propagated activity, including SD at 20-150 $\mu \mathrm{m} / \mathrm{sec}$ (Leao, 1944; Nicholson et al., 1978; Somjen et al., 1992) and calcium waves at 25-100 $\mu \mathrm{m} / \mathrm{sec}$ (Newman and Zahs, 1997; Kunkler and Kraig, 1998; MartinsFerreira et al., 2000). Other unique characteristics of this propagated activity include a stable extracellular DC potential, no change in blood vessel diameter, and repeatability at short intervals (Chen et al., 1999a). Also differentiating this spreading phenomenon from classic SD is its occurrence in the cerebellum without radical substitution of the ionic makeup of the extracellular environment (Nicholson and Kraig, 1975; Tobiasz and Nicholson, 1982).

The initial study described and characterized the basic properties of this propagating acidification and depression (Chen et al., 1999a). The goal of the present study was to gain insights into underlying mechanisms by evaluating the effective stimulation parameters, contribution of presynaptic and postsynaptic components, involvement of various neurotransmitters and receptors, and the role of extracellular or intercellular messengers, or both. This study demonstrates that both presynaptic and postsynaptic structures are involved and that extracellular $\mathrm{Ca}^{2+}$, AMPA receptors, metabotropic glutamate receptors (mGluRs), and nitric oxide (NO) all contribute. Purinergic receptors are unlikely to be involved.

Parts of this paper have been published previously in abstract form (Chen et al., 1999b). 


\section{MATERIALS AND METHODS}

Animal preparation. All animal experimentation was approved by the Institutional Animal Care and Use Committee of the University of Minnesota and conducted in conformity with the National Institutes of Health Guide for the Care and Use of Laboratory Animals. Experimental details on the animal preparation and optical imaging techniques have been provided in previous publications (Chen et al., 1998; Hanson et al., 2000) and therefore are only briefly described here. Adult Sprague Dawley rats (Harlan, Indianapolis, IN) of either sex (200-400 gm) were anesthetized by intramuscular injection of a solution of ketamine (60 $\mathrm{mg} / \mathrm{kg}$ ) and xylazine $(3 \mathrm{mg} / \mathrm{kg})$. The trachea was cannulated for artificial respiration, as was the jugular vein for the administration of fluids. Body temperature was feedback-regulated. The electrocardiogram was monitored to assess the depth of anesthesia, allowing anesthetic to be supplemented as needed. After a craniotomy and creation of a watertight chamber of acrylic around Crus I and II, the exposed surface was stained by superfusion with a $10 \mathrm{~mm}$ solution of neutral red (3-amino- $m$ dimethylamino-2-methylphenazine hydrochloride; Sigma, St. Louis, MO) for 2-3 hr. An intravenous injection of neutral red (1 $\mathrm{ml}$ at $35 \mathrm{~mm}$ ) was used to supplement the bath staining. After staining, the neutral red solution in the chamber was thoroughly and repeatedly washed out, and the chamber was refilled with Ringer's solution. The chamber was periodically rinsed with fresh normal Ringer's solution that was repeatedly gassed with $95 \% \mathrm{O}_{2}$ and $5 \% \mathrm{CO}_{2}$ to maintain a stable $\mathrm{pH}$ of 7.4 in the chamber and in the interstitial environment of the cerebellum.

Transgenic mice with an NO synthase (NOS) gene mutation were also used. A breeding pair of mice homozygous for a targeted mutation (B6;129S-Nos $1^{\text {tmlplh }}$ ) disrupting the neuronal NOS gene was obtained from JAX mice (Bar Harbor, ME). These animals were bred and the offspring were used in these experiments when they reached 20-40 gm. The surgical and experimental procedures were similar to those used in the rat, with the required scaling of the stereotaxic apparatus, physiological monitoring, and respiratory control system needed for the mouse. Also, an intraperitoneal injection of neutral red $(0.3-0.6 \mathrm{ml}, 35 \mathrm{~mm})$ was used to augment and prolong the staining of the cerebellar cortex.

Electrical stimulation and electrophysiological monitoring techniques. Parallel fiber stimulation was delivered by a tungsten microelectrode (1-3 $\mathrm{M} \Omega$ ) placed just below the cerebellar surface. The stimulation parameters consisted of a train of stimuli delivered at $5-75 \mathrm{~Hz}$ for $2-20 \mathrm{sec}$. Individual stimuli had pulse durations of $100-300 \mu \mathrm{sec}$ and amplitudes of 100-300 $\mu \mathrm{A}$. Stimulation intensity including frequency and amplitude were varied in some experiments to evaluate the dependence of spreading acidification on stimulation parameters. In some experiments, extracellular recordings of the evoked field potentials were obtained with glass microelectrodes $(2 \mathrm{M} \mathrm{NaCl}, 2-5 \mathrm{M} \Omega$ ) using conventional electrophysiological techniques (Chen et al., 1998, 1999a). The field potentials were digitized $(50 \mathrm{kHz})$, averaged on-line, and stored for additional off-line analysis.

To evaluate the excitability of the cerebellar cortex in relation to the spreading optical response, extracellular field potentials were recorded simultaneously with the acquisition of the images. Two stimulation electrodes were placed on the surface. The first electrode was used to evoke spreading acidification, and the second electrode placed anterior to the first was used to activate a test group of parallel fibers for assessing the excitability of the cerebellar circuit. The resultant parallel fiber volley (positive-negative-positive deflection; $\mathrm{P}_{1}-\mathrm{N}_{1}-\mathrm{P}_{2}$ components) and postsynaptic response (longer latency negative deflection; $\mathrm{N}_{2}$ component) were recorded "on beam" relative to the second stimulation electrode (Eccles et al., 1967; Chen et al., 1999a). The capture of each image was synchronized with the field potential recordings. The amplitude of $\mathrm{P}_{1}$ to $\mathrm{N}_{1}$ was used as a measure of parallel fiber excitability, and the amplitude of $\mathrm{N}_{2}$ was used as a measure of the postsynaptic response. In several experiments we also examined the field potentials evoked as a function of stimulation frequency and amplitude. Of interest was the accumulative effect of the stimulus train required to evoke spread; therefore, the "summed" field potential evoked by the initial $1 \mathrm{sec}$ of the train was used. Because at higher stimulus frequencies the field potentials invariably decreased in size with time, this provided a measure of the accumulated response to the stimulus train. Both the presynaptic and postsynaptic components were determined.

Optical imaging. After staining while still mounted in the stereotaxic frame, the animal was placed on a large stage with precision $x$ and $y$ translation. Modified Zeiss (Thornwood, NY) optics for epifluorescence imaging was mounted above the animal. Using a stabilized xenonmercury light source, the excitation light was passed through a bandpass filter $(546 \pm 10 \mathrm{~nm})$ while emitted light passed through a long-pass filter $(\geq 620 \mathrm{~nm})$. The cutoff wavelength of the dichroic mirror placed between the excitation and emission filters was $580 \mathrm{~nm}$. Images were taken with cooled CCD cameras (PXL-37 with $512 \times 512$ pixels or Quantix 57 with $530 \times 512$ pixels, both with 12 bit digitization; Roper Scientific, Tucson, AZ). The resolution using the PXL-37 camera was reduced to $170 \times 170$ by binning pixels on the CCD chip, and when using a $2 \times$ objective, the final image resolution was $14 \times 14 \mu \mathrm{m}$. The resolution using the Quantix 57 camera was reduced to $176 \times 170$ by binning pixels on the CCD chip, and when using a $2 \times$ objective, the final image resolution was $13 \times 13$ $\mu \mathrm{m}$. The camera was focused $100-300 \mu \mathrm{m}$ below the surface of the cerebellar cortex.

The experimental protocol included obtaining a sequence of images. This sequence consisted of a series of 20 "background" fluorescence images, followed by a surface stimulation for $2-10 \mathrm{sec}$. During and after the stimulation, a second series of images was acquired. The entire sequence usually consisted of 320-820 images, and each image was acquired with an integration time (camera exposure time) of 70-120 msec. The time between images was 40-50 msec for the PXL-37 camera and $<0.1 \mathrm{msec}$ for the Quantix 57 camera. No frame averaging was undertaken. Quantification of the optical signal in each image in the series, $F_{\mathrm{i}}$, was based on the net fluorescence change as a function of the background fluorescence, $F_{\mathrm{B}}$; that is, $\Delta F=\left(F_{\mathrm{i}}-F_{\mathrm{B}}\right) / F_{\mathrm{B}}$. The average of the 20 background frames was used as $F_{\mathrm{B}}$. Then the average $\Delta F$ in regions of interest was determined. For most experiments, the region of interest was the folium stimulated. In some experiments, several regions of interest were defined at various locations, and the average $\Delta F$ in each region was determined. Figure display was based on the subtraction of $F_{\mathrm{B}}$ from the entire sequence of images, $F_{\mathrm{i}}$, and displaying the resultant images.

Pharmacological manipulations and drugs. To gain insights into the neurotransmitter systems involved in the spreading optical response, various receptor antagonists were applied to the cerebellar cortex. To alter the production of NO, a nitric oxide synthase inhibitor and NO donor were used. To examine whether the optical signals were attributable to swelling of cellular processes or the accompanying reduction in extracellular space (Holthoff and Witte, 1996), furosemide, a blocker of anion transport (Ransom et al., 1985; Holthoff and Witte, 1996; Muller and Somjen, 1999), was used. For most compounds, stock solutions (1-10 $\mathrm{mm}$ ) were made in saline, stored at $-20^{\circ} \mathrm{C}$ and diluted to the required concentration in normal Ringer's solution before each experiment. If required, the solution was prepared fresh on the day of use. All drugs were applied to the exposed cerebellar surface by superfusion of the drug solution in the chamber. If needed, drugs were removed by repeated washout of the chamber with normal Ringer's solution. For repeated testing of a pharmacological agent or different agents, separate animals were used. The number of animals reported for each drug refers to experiments performed in different animals.

$(R S)$ - $\alpha$-Methyl-4-carboxyphenylglycine (MCPG) and $(R S)-\alpha-$ methylserine- $O$-phosphate (MPPG) were purchased from Tocris Cookson Inc. (Ballwin, MO). Neutral red, $N$-nitro-L-arginine (NLA), furosemide, and suramin were purchased from Sigma (St. Louis, MO). The following drugs were obtained from Research Biochemicals (Natick, MA): L(+)-2-amino-3-phosphonopropionic acid (AP-3), $\mathrm{D}(-)$-2-amino-5-phosphonopentanoic acid (AP-5), (-)-bicuculline methiodide, $1(S), 9(R)$-(bicuculline), 6-cyano-7-nitroquinoxaline-2,3-dione disodium (CNQX), pyridoxal-phosphate-6-azophenyl-2',4'-disulfonic acid tetrasodium (PPADS), ( \pm )-3-amino-2-(4-chlorophenyl)-2-hydorxypropylsulfonic acid (saclofen), $S$-nitroso- $N$-acetylpenicillanine (SNAP), and tetrodotoxin (TTX).

\section{RESULTS}

\section{Spreading acidification and depression: dependence on stimulus parameters and neuronal activation}

Electrical stimulation of the cerebellar cortex with a brief train of pulses evoked a narrow beam of increased fluorescence transversely across the folium (Fig. $1 A$ ). This beam-like activity is attributable to the activation of a bundle of parallel fibers and their postsynaptic targets and in large part is attributable to the resulting intracellular acidification (Chen et al., 1996, 1998). In some preparations, this activity propagated throughout the folium and into neighboring folia (Fig. $1 A$ ). In this example, at $\sim 6.1$ $\mathrm{sec}$ from the onset of stimulation, the optical response began to 

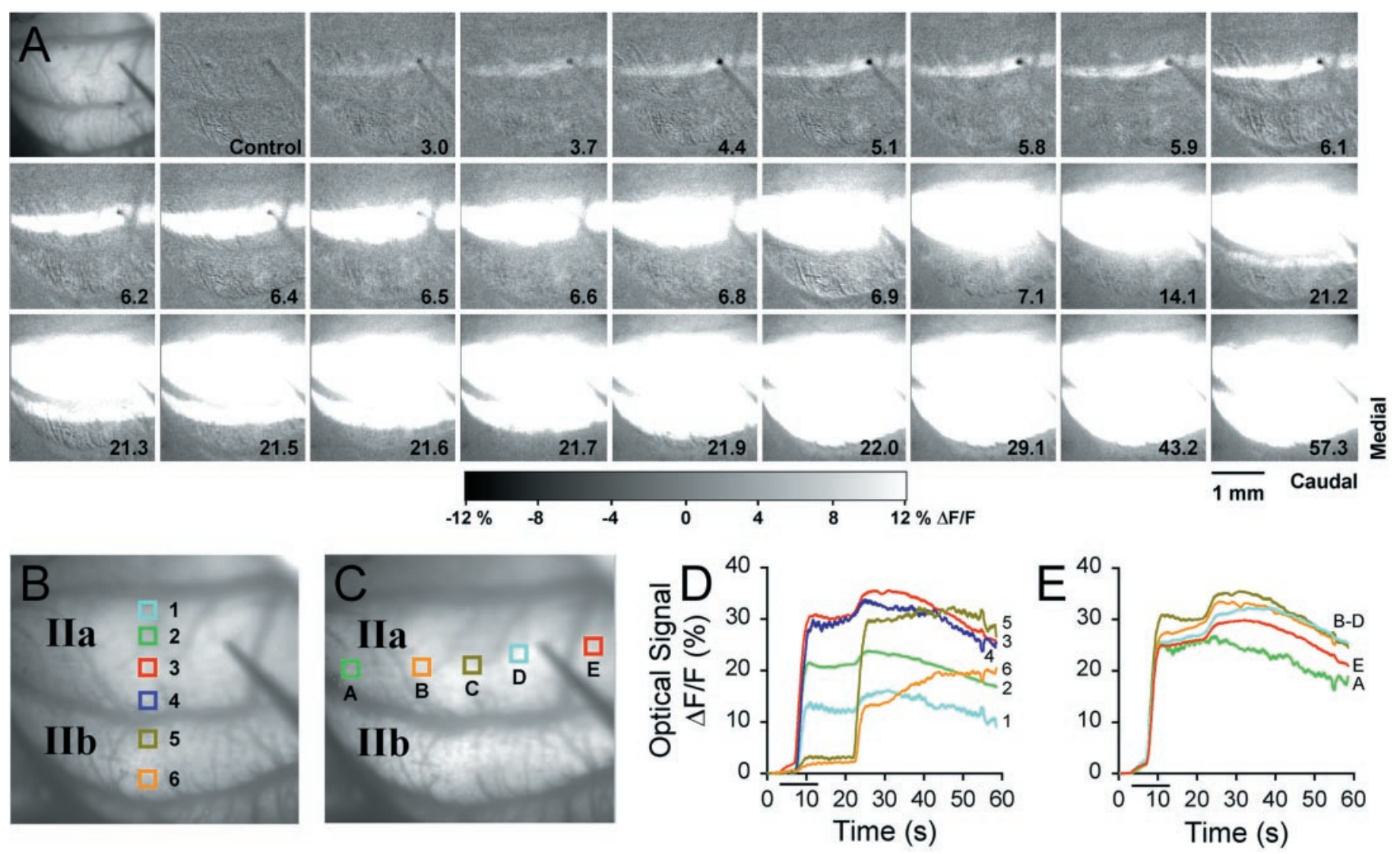

Figure 1. Propagation of the optical response in Crus IIa and b. A, Series of optical images (stimulation minus background) illustrating the effect of surface stimulation $(150 \mu \mathrm{A}, 150 \mu \mathrm{sec}$ pulses at $10 \mathrm{~Hz}$ for $10 \mathrm{sec})$. The first image is a background image and also shows the position of the stimulating electrode (see $B, C$ ). Numbers are the times in seconds relative to the onset of stimulation. Different time intervals are shown to highlight different aspects of the propagation. $B, C$, Background images of the folia and the regions of interest (boxes with numbers or letters) at which the fluorescence changes were measured. Boxes were selected to show the propagation parasagittally across the folia in $B$ and transversely within a folium in $C$. $D$, Intensity of optical response as percentage of $\Delta F / F$ as a function of time for the regions of interest in $B$. $E$, Intensity of optical response as percentage of $\Delta F / F$ as a function of time for the regions of interest in $C$. For this and the following figures, the bar beneath the $x$-axis denotes time of stimulation. The orientation of the image and scale bar are as indicated.

spread orthogonally to the parallel fiber beam moving rapidly across the surface of the folium. By $6.6 \mathrm{sec}$, the optical signal had reached the posterior edge of Crus IIa, and by $6.9 \mathrm{sec}$, it had reached the anterior edge. The propagation speed across Crus IIa was $782 \mu \mathrm{m} / \mathrm{sec}$. After an additional delay of $7.5 \mathrm{sec}$ attributable to traversing the intrasulcal distance, the optical response spread to the anterior edge of the neighboring folium, Crus IIb (Fig. $1 A$, 14.1). The optical signal then spread rapidly across the surface of Crus IIb, reaching its posterior boundary within $22.0 \mathrm{sec}$.

Several $10 \times 10$ pixel regions of interest were selected in the parasagittal plane (Fig. 1B) and in the transverse plane (Fig. 1C) to illustrate the amplitude $(\Delta F / F)$ and time course of the optical signal (Fig. 1D,E). During the first $6 \mathrm{sec}$ of the stimulus train and before the onset of spreading acidification, the optical signal was $\sim 0.5 \%(\Delta F / F)$ and remained confined to a beam $\sim 250 \mu \mathrm{m}$ in width in the middle of the folium. Once the optical signal spread, it increased to $30 \% \Delta F / F$ (regions of interest near the center of Crus IIa). The fluorescence remained elevated at this level over the next $60 \mathrm{sec}$, although the stimulus train had ended (Fig. 1D). The long delays in the arrival of the optical signal in Crus IIb and the rapid but persistent increase in fluorescence are also evident in the plots of $\Delta F / F$. Within Crus IIa, the spread of the optical signal was initiated nearly simultaneously along the parallel fiber beam (Fig. 1E).
Stimulus frequency and amplitude were important factors in determining whether spreading acidification was initiated, with more intense stimulation increasing the likelihood of spreading acidification. As shown in Figure 2A, increasing the amplitude of stimulation from 150 to $250 \mu \mathrm{A}$ increased the intensity of the optical beam, but spreading acidification was not evoked until the stimulation amplitude reached $300 \mu \mathrm{A}$. Similarly, increasing the stimulation frequency from 10 to $15 \mathrm{~Hz}$ enhanced the initial optical beam, but spreading was not evoked until the stimulation frequency was increased to $20 \mathrm{~Hz}$. Increasing the duration of the stimulus train had a similar effect, with longer-duration trains more likely to result in spreading acidification (data not shown). The probability of evoking spread as a function of stimulation frequency and amplitude is summarized in Figure $2 B$. The data are based on a subset of 51 animals in which stimulation frequency or amplitude was adjusted to produce spreading acidification. In general, greater stimulation intensity increased the probability of evoking spreading acidification. In these animals, spreading acidification was invariably evoked with the stimulation frequencies of $40-50 \mathrm{~Hz}$ and amplitudes of $250-300 \mu \mathrm{A}$. However, in some animals, spreading acidification could not be evoked regardless of the stimulation parameters. Spreading acidification was observed in 100 of 145 animals (69\%), an occurrence rate similar to that reported previously (Chen et al., 1999a). 

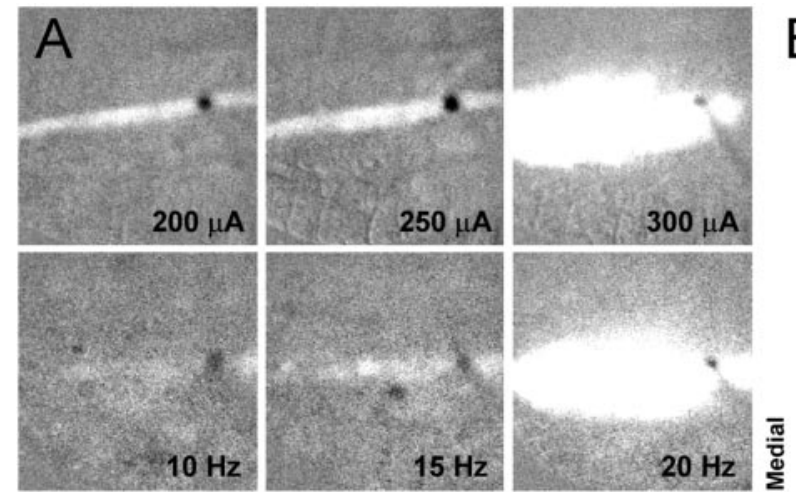

Caudal

$1 \mathrm{~mm}$
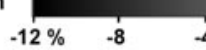

0
B

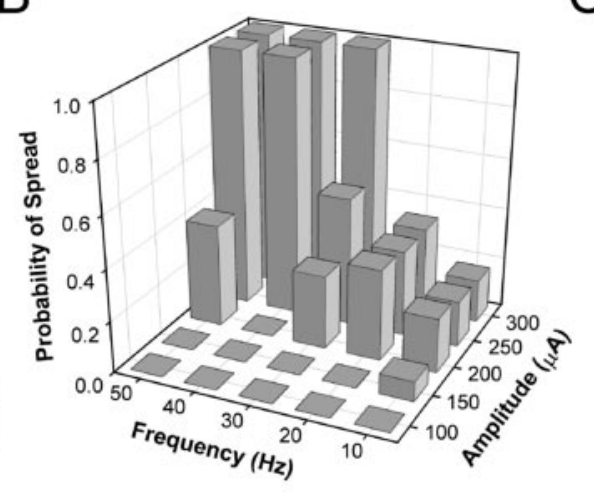

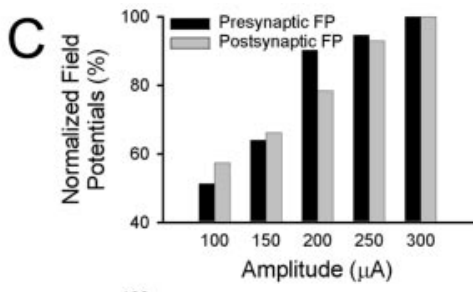

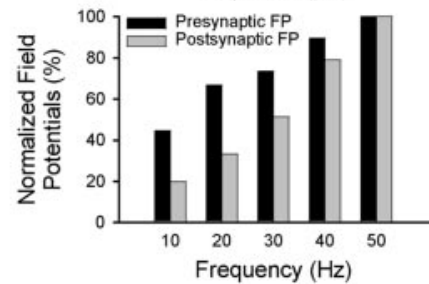

Figure 2. Relationship between stimulation parameters and optical electrophysiological responses. $A$, Effect of stimulation amplitude and frequency on the optical response. Top row, Effect of amplitude. At the same stimulation frequency ( $10 \mathrm{~Hz}$ for $5 \mathrm{sec}$ ), when amplitude was changed from 200 to 250 $\mu \mathrm{A}$, the evoked optical response was enhanced, and at $300 \mu \mathrm{A}$, spread was evoked. Note that the decrease in fluorescence at the site of the stimulating electrode is accentuated by increasing stimulation amplitude. Bottom row, Effect of stimulation frequency. Layout is similar to the top row, except that stimulation frequency was varied as indicated. Stimulation amplitude and duration were constant $(250 \mu \mathrm{A}$ and 2 sec). B, Relationship between the probability of evoking spreading acidification and stimulation frequency and amplitude. Data were obtained from 215 experiments in 51 animals in which spread was evoked at some combination of stimulation parameters. $C$, Effects of stimulation intensities on accumulative field potentials. Normalized accumulative field potentials as a function of stimulation amplitude (top, at $50 \mathrm{~Hz})$ and stimulation frequency $($ bottom, at $100 \mu \mathrm{A})$ are shown.

More intense stimulation evoked a larger total presynaptic and postsynaptic response over the stimulation period. As shown for the representative example in Figure $2 C$, increasing the stimulation amplitude from 100 to $300 \mu \mathrm{A}$, while holding stimulation frequency constant, led to a progressive increase in both the presynaptic and postsynaptic components of the summed extracellular field potential. A similar increase in the summed field potential was observed with increasing stimulus frequency from 10 to $50 \mathrm{~Hz}$ while holding amplitude constant (Fig. 2C).

\section{Dependence on presynaptic and postsynaptic activation}

A fundamental question is whether spreading acidification occurs with only the activation of the parallel fibers, i.e., the presynaptic elements. To block synaptic transmission as completely as possible, the chamber was filled with nominally $\mathrm{Ca}^{2+}$-free Ringer's solution $\left(0 \mathrm{Ca}^{2+}, 2 \mathrm{mM} \mathrm{Mg}^{2+}\right.$, and $2 \mathrm{~mm}$ EGTA) for $30 \mathrm{~min}$. Surface stimulation in normal Ringer's solution (control) produced a typical beam of increased fluorescence that subsequently spread throughout the folium (Fig. 3A,F). After superfusion with nominally $\mathrm{Ca}^{2+}$-free Ringer's solution, spreading acidification was not evoked either at the same stimulus parameter (Fig. $3 B$ ) or with increasing stimulation frequency (Fig. $3 C, D$ ). Electrophysiological recordings (Fig. $3 G$ ) show that $\mathrm{N}_{2}$ of the field potential was abolished, whereas $\mathrm{P}_{1}-\mathrm{N}_{1}$ was unaffected. The weaker optical beam at the same stimulation parameters after superfusion with nominally $\mathrm{Ca}^{2+}$-free Ringer's solution (Fig. 3 , compare $A$ and $B$ ) is attributable to the block of synaptic transmission and is consistent with our previous finding that both presynaptic and postsynaptic elements contribute to the optical signal (Chen et al., 1998). After return to normal Ringer's solution, stimulation at the original parameters evoked spreading acidification (Fig. 3E). Although the amplitude and extent of the spreading acidification were reduced after washout, the temporal profile of optical signal reveals a similar, rapid increase at spread onset (Fig. $3 F$ ). The partial recovery of the spreading acidification likely reflects the loss of the dye attributable to repeated washing and the failure to completely restore the extracellular environment. Similar results were obtained in four animals in which nominally $\mathrm{Ca}^{2+}$-free Ringer's solution was used. Stimulation up to $100 \mathrm{~Hz}$ and $400 \mu \mathrm{A}$ did not evoke spreading acidification. Therefore, extracellular $\mathrm{Ca}^{2+}$ is a requirement, and activation of only parallel fibers is insufficient to produce spreading acidification.

Evoking spreading acidification required the activation of neurons and functioning voltage-gated $\mathrm{Na}^{+}$channels. An example is shown in Figure 3H, in which surface stimulation failed to evoke either an optical beam or spreading acidification regardless of stimulus parameters after superfusion of Ringer's solution containing $10 \mu \mathrm{M}$ TTX. A complete block of spreading acidification with TTX was observed in four animals. Therefore, spreading acidification is dependent on neuronal activation, and local depolarization of neurons or glia directly around the electrode site is not capable of evoking spreading acidification. This finding also suggests that the activation of a bundle of parallel fibers contributes to the generation and the geometry of spreading acidification.

\section{Involvement of glutamate receptors}

A series of experiments were performed to evaluate the dependence of spreading acidification on non-NMDA, NMDA, and mGluRs. When the competitive AMPA glutamate receptor antagonist CNQX was added to the Ringer's solution, the threshold for spreading acidification increased. As shown for the example in Figure 4, surface stimulation produced the characteristic beam and spreading response with a peak $\Delta F / F$ of $\sim 17 \%$ (Fig. $4 A$ ). After application of $50 \mu \mathrm{M} \mathrm{CNQX,} \mathrm{stimulation} \mathrm{at} \mathrm{the} \mathrm{same}$ parameters did not evoke spreading acidification. Note that the amplitude of the initial beam was reduced $\sim 60 \%$ but not completely abolished, also consistent with our previous finding that both presynaptic and postsynaptic elements contribute to the optical response (Chen et al., 1998). Field potential recordings reveal a complete loss of the postsynaptic negativity, with no effect on the parallel fiber volley (Fig. $4 B$ ). Increasing stimulation frequency to $30 \mathrm{~Hz}$ did not evoke spreading acidification, whereas stimulation at $40 \mathrm{~Hz}$ did (Fig. $4 A$ ), although the amplitude was attenuated. After washout of the CNQX, surface stimulation at $20 \mathrm{~Hz}$ evoked spreading acidification (data not shown). In three 


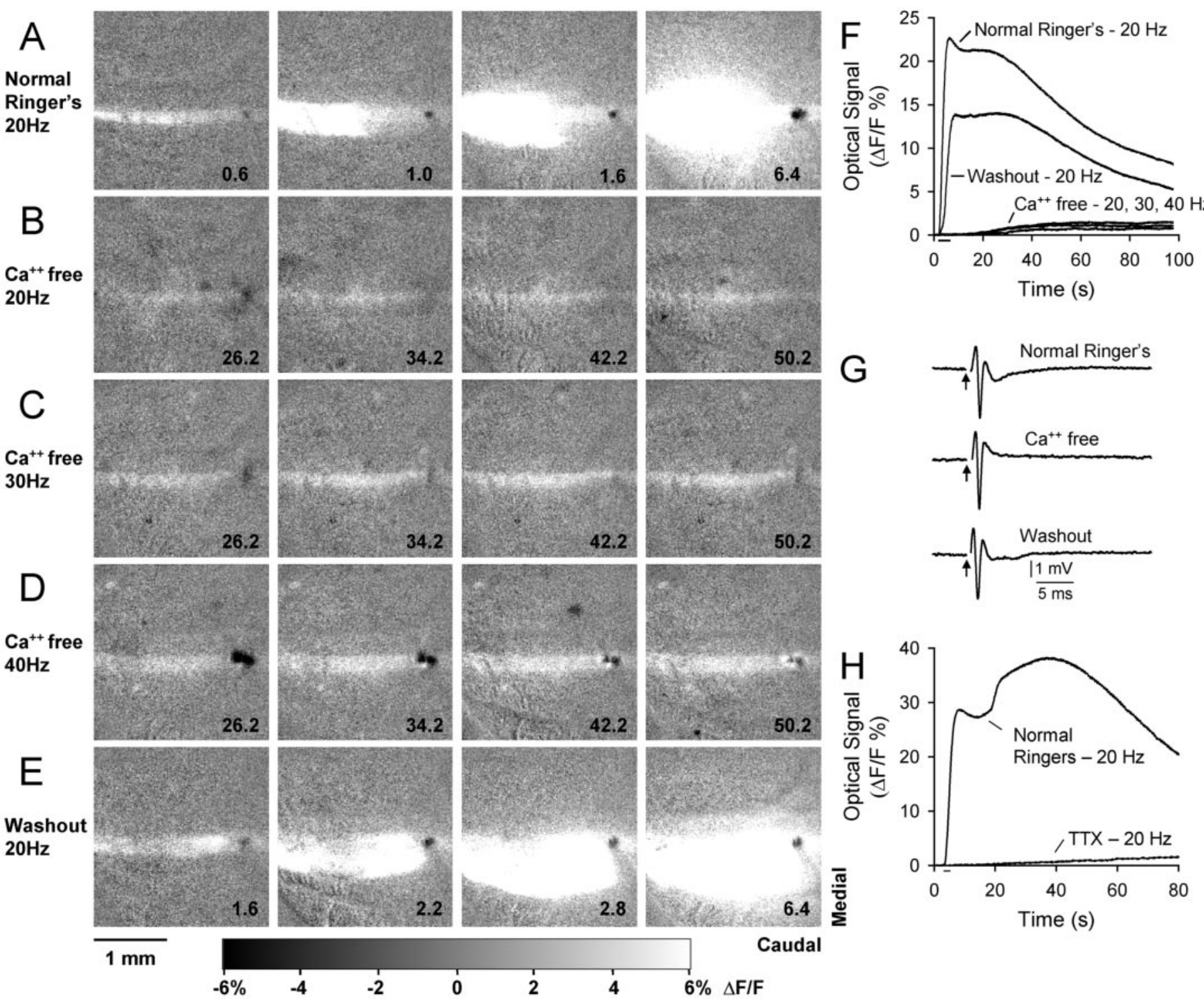

Figure 3. Effect of nominally $\mathrm{Ca}^{2+}$-free Ringer's solution $\left(0 \mathrm{Ca}^{2+}, 2 \mathrm{mM} \mathrm{Mg}^{2+}\right.$, and $2 \mathrm{mM}$ EGTA) on spreading acidification. $A$, Sequence of images showing the spreading acidification evoked by surface stimulation $(200 \mu \mathrm{A}, 15 \mathrm{~Hz}$ for $5 \mathrm{sec}) . B-D$, Attempts to evoke spreading acidification in the presence of nominally $\mathrm{Ca}^{2+}$-free Ringer's solution. The results of three different stimulation frequencies are shown. $E$, After return to normal Ringer's solution, stimulation at $20 \mathrm{~Hz}$ evoked spreading acidification. $F$, Change in fluorescence $(\Delta F / F)$ as a function of time for each series. $G$, Field potential recordings in normal Ringer's solution, nominally $\mathrm{Ca}^{2+}$-free Ringer's solution, and after washout. Arrow, Stimulation onset; gap in the record, stimulus artifact removed. $H$, Effect of TTX on spreading acidification. In normal Ringer's solution, the spreading acidification is evident but is abolished by the application of TTX $(10 \mu \mathrm{M})$.

additional animals, CNQX blocked spreading acidification, but increasing the stimulation intensity (current, frequency, or duration) evoked spreading acidification. These findings show that the increase in postsynaptic excitability mediated via AMPA receptors contributes to spreading acidification.

Metabotropic glutamate receptors, particularly the $\mathrm{mGluR}_{1}$ subtype, are found on Purkinje cells (Martin et al., 1992) and produce significant excitatory currents in response to high stimulus frequencies (Batchelor et al., 1994; Finch and Augustine, 1998; Takechi et al., 1998). Activation of these receptors triggers several intracellular signaling cascades including release of intracellular calcium via inositol-1,4,5-triphosphate (Finch and Augustine, 1998). Because evoking spreading acidification was dependent on stimulation frequency (Fig. 2), the role of metabotropic glutamate receptors was evaluated by using the mGluR antago- nist MCPG. As shown in Figure 4, $C$ and $D$, surface stimulation initially evoked a beam-like optical response that spread. Thirty minutes after the application of MCPG, surface stimulation using the same parameters failed to produce spreading acidification. However, spreading acidification was evoked when the stimulation frequency was increased to $40 \mathrm{~Hz}$ (Fig. 4C), albeit diminished in amplitude and speed as discussed above. The field potential recordings reveal identical electrophysiological responses before and after the application of MCPG (Fig. 4D). As a demonstration of its efficacy, MCPG reduced the intensity of the initial beam-like optical response evoked by surface stimulation. In experiments in which the MCPG was washed out, spread was evoked at the original stimulation parameters. Similar results were obtained in three animals in which MCPG prevented spreading acidification at the control stimulation parameters, but 

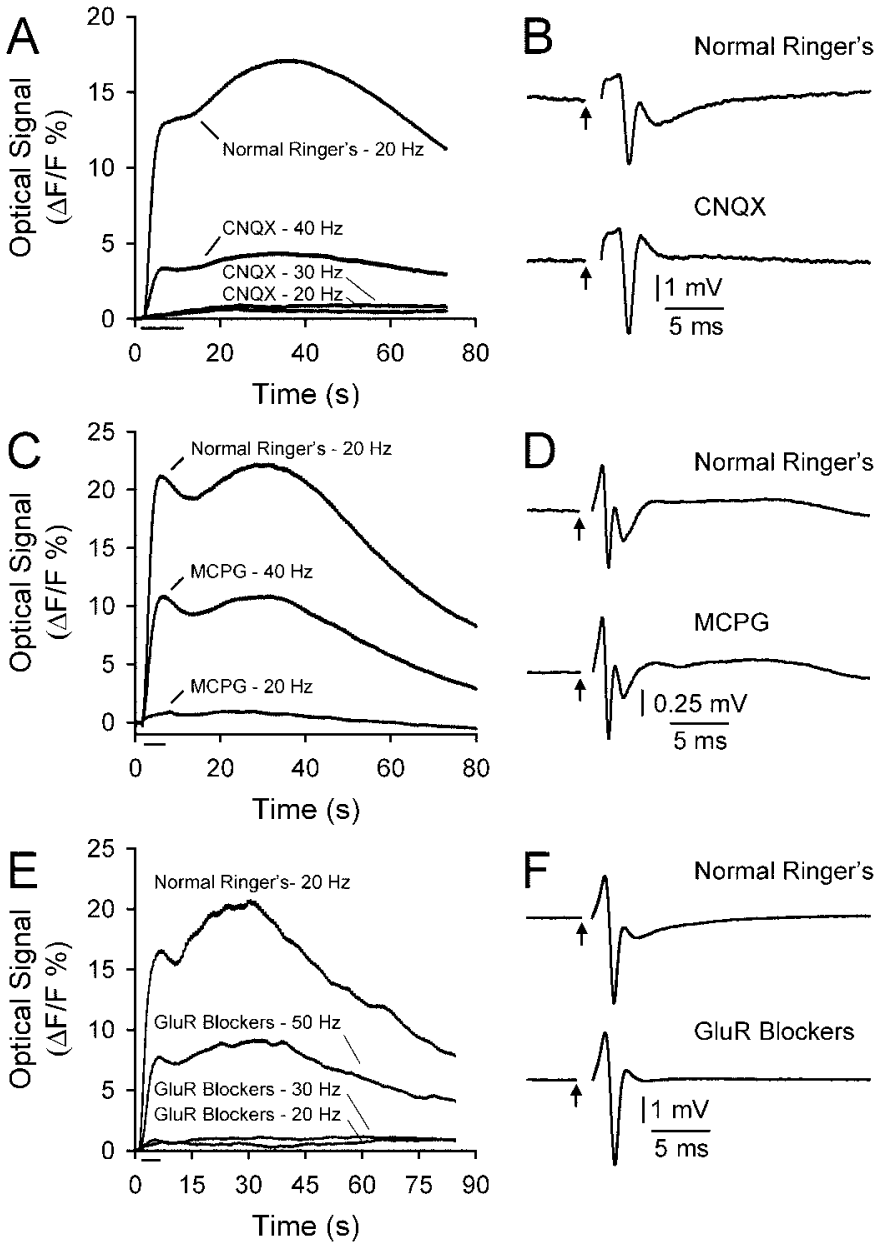

Figure 4. Effect of glutamate antagonists on spreading acidification. A, Change in fluorescence as a function of time in normal Ringer's solution and in normal Ringer's solution containing $50 \mu \mathrm{M}$ CNQX. The latter includes series of three stimulation frequencies as indicated. In normal Ringer's solution, spreading acidification was evoked at $20 \mathrm{~Hz}$; after the application of CNQX $(50 \mu \mathrm{M})$, spreading acidification was evoked at 40 $\mathrm{Hz}$ but not 20 or $30 \mathrm{~Hz}$. Stimulation amplitude and duration were kept constant $(300 \mu \mathrm{A}, 20 \mathrm{~Hz}$ for $10 \mathrm{sec})$. B. Field potential recordings in normal Ringer's solution and after application of CNQX. $C$, Similar layout as in $A$, but MCPG (1 mM) was applied. $D$, Field potential recordings in normal Ringer's solution and after application of MCPG. $E$, Similar layout as in $A$, but a combination of both AMPA and mGluR antagonists was used. These GluR blockers included $20 \mu \mathrm{M}$ CNQX, $1 \mathrm{~mm}$ MCPG, and $1 \mathrm{~mm}$ MPPG. $F$, Field potential recordings in normal Ringer's solution and after application of GluR blockers.

increasing the stimulation frequency to 40 or $50 \mathrm{~Hz}$ did evoke spreading acidification. These results indicate that activation of postsynaptic mGluRs contributes to spreading acidification, similar to that of AMPA receptor.

In three additional animals, the mGluR antagonist MPPG was also used. MPPG blocks $\mathrm{mGluR}_{4}$-type receptors that are found presynaptically on the parallel fibers (Mateos et al., 1998). MPPG had no effect on the spread (data not shown).

To determine the effect of blocking ionotropic and metabotropic glutamate receptors at the parallel fiber-Purkinje cell synapse, AMPA and mGluR antagonists were applied together to determine whether blocking both AMPA and metabotropic receptors completely prevented spreading acidification. As shown in Figure $4 E$, this combination of glutamate antagonists increased the threshold for spreading acidification. However, in-

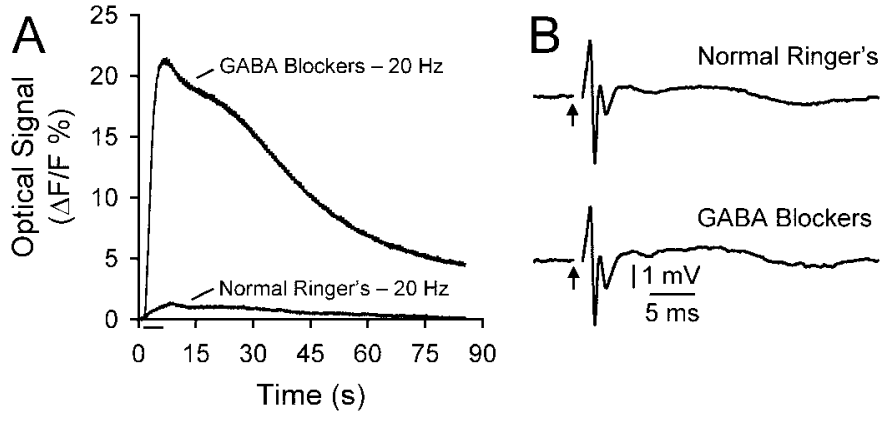

Figure 5. Effects of GABA blockade on spreading acidification. $A$, Change in fluorescence as a function of time in normal Ringer's solution and in normal Ringer's solution containing GABA blockers. The same stimulation parameters were used for both conditions $(300 \mu \mathrm{A}, 20 \mathrm{~Hz}$ for $5 \mathrm{sec}$ ). GABA blockers included $100 \mu \mathrm{M}$ bicuculline and $250 \mu \mathrm{M}$ saclofen. $B$, Field potential recordings in normal Ringer's solution and after application of GABA blockers.

creasing the stimulation frequency to $50 \mathrm{~Hz}$ evoked spreading acidification. Field potential recordings reveal a complete loss of the postsynaptic negativity, with no effect on the parallel fiber volley (Fig. $4 F$ ). Similar findings were obtained in four animals. Therefore, additional mechanisms are likely involved in spreading acidification.

Additionally, NMDA glutamate receptor antagonists AP-3 (100 $\mu \mathrm{M}$, three animals) and AP-5 (100 $\mu \mathrm{M}$, three animals) had no significant effect on spreading acidification, a finding not unexpected, because the ketamine at the doses used in the anesthetic would have blocked NMDA receptors (Lang, 2001). Furthermore, Purkinje cells in the adult rat cerebellum do not have NMDA receptors (Farrant and Cull-Candy, 1991).

\section{Involvement of GABAergic neurotransmission}

The parallel fibers synaptically activate several inhibitory interneurons, including the basket and stellate cells, which in turn have Purkinje cells as their postsynaptic target (Eccles et al., 1967). Also, Purkinje cell axon collaterals inhibit other Purkinje cells. Both the inhibitory interneurons and Purkinje cells use GABA as their neurotransmitter (Ito, 1984). Because AMPA and mGluR antagonists increased the threshold for evoking spread, it would be expected that blocking GABAergic transmission would lower the threshold. This prediction was confirmed in experiments in which both $\mathrm{GABA}_{\mathrm{A}}$ and $\mathrm{GABA}_{\mathrm{B}}$ receptor antagonists (bicuculline and saclofen, respectively) were added to the Ringer's solution (Fig. 5). Initially, stimulation at $20 \mathrm{~Hz}$ evoked an optical beam but did not produce spread. After addition of the GABA blockers, the beam evoked by surface stimulation at $20 \mathrm{~Hz}$ increased in width and intensity and subsequently spread (Fig. 5A). After the GABA blockers, the presynaptic component of the field potential recordings was identical, and there was a small increase in the postsynaptic response (Fig. 5B). Similar findings were obtained in three animals, in which the GABA blockers reduced the threshold for spreading acidification.

\section{Involvement of nitric oxide}

How does spreading acidification and depression propagate? One possible mechanism is that a diffusible substance is released in the extracellular space. A potential candidate for such an extracellular messenger is NO, which is generated in the cerebellar cortex after surface stimulation (Shibuki and Kimura, 1997; Kimura et al., 1998). The target of NO, guanyl cyclase, is primarily localized in cerebellar Purkinje cells (Ariano et al., 1982; 

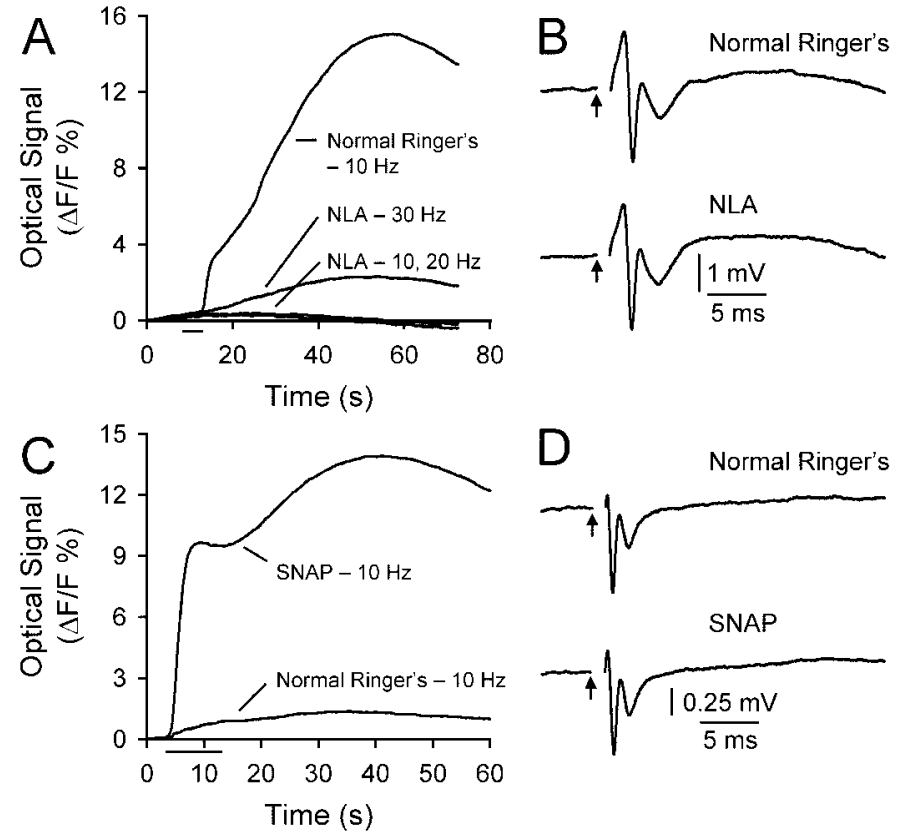

D
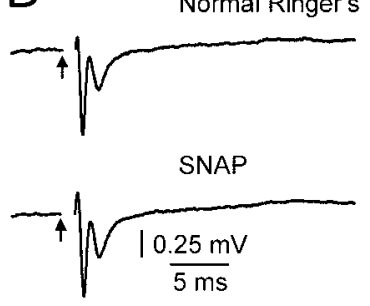

Figure 6. Relationship between NO production and spreading acidification. $A$, Effect of the NOS inhibitor NLA on spreading acidification. Change in fluorescence is shown as a function of time for series in normal Ringer's solution and in normal Ringer's solution containing 1 mM NLA. The latter includes series of three stimulation frequencies as indicated. In normal Ringer's solution, spreading acidification was evoked at $10 \mathrm{~Hz}$; after the application of NLA, spreading acidification was evoked at 30 $\mathrm{Hz}$ but not 10 or $20 \mathrm{~Hz}$. Stimulation amplitude and duration $(200 \mu \mathrm{A}, 10$ $\mathrm{Hz}$ for $5 \mathrm{sec}$ ) were kept constant. $B$, Field potential recordings in normal Ringer's solution and after application of NLA. $C$, Effect of the NO donor SNAP on spreading acidification. Change in fluorescence is shown as a function of time for series in normal Ringer's solution and in normal Ringer's solution containing 2 mM SNAP. Surface stimulation (300 $\mu \mathrm{A}$, $20 \mathrm{~Hz}$ for $10 \mathrm{sec}$ ) produced a strong beam-like optical response but not spreading acidification. After the application of SNAP, spreading acidification was evoked. $D$, Field potential recordings in normal Ringer's solution and after application of SNAP.

Boxall and Garthwaite, 1996). The involvement of NO was assessed using the NOS inhibitor NLA. After evoking spreading acidification with surface stimulation at $10 \mathrm{~Hz}$ (Fig. 6A), the cerebellar cortex was superfused with Ringer's solution containing $1 \mathrm{~mm}$ NLA. Stimulation at 10 and $20 \mathrm{~Hz}$ evoked only a beam. Spreading acidification, albeit reduced in amplitude and speed, was only evoked when the stimulation frequency was increased to $30 \mathrm{~Hz}$. NLA had no effect on the field potential recordings (Fig. $6 B$ ), as reported previously (Iadecola et al., 1995). Similar results were observed in six animals.

To further examine the contribution of NO to spreading acidification, the effect of the NO donor SNAP was determined. As described above, spreading was evoked in $69 \%$ of the animals. SNAP was added to the Ringer's solution in experiments in which spreading acidification could not be evoked regardless of the stimulation intensity. An example is shown in Figure $6 C$, in which intense surface stimulation produced a strong, wide, beam-like optical response that failed to spread. After superfusion with $2 \mathrm{~mm}$ SNAP, the same stimulus parameters evoked an optical beam that propagated throughout the folium. Similar results were observed in four animals. The field potential recordings were not altered by the application of SNAP (Fig. 6D). These results demonstrate that NO is a modulator of spreading acidification.

Antagonists of AMPA and mGlu receptors and NOS blockers

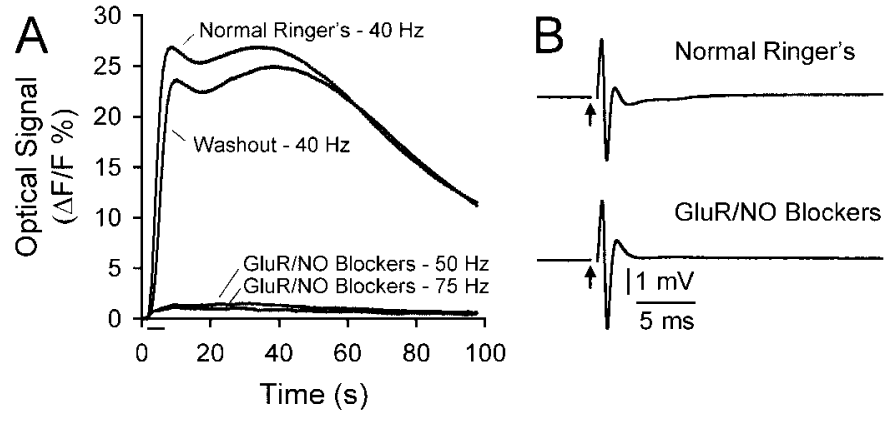

Figure 7. Effect of AMPA antagonists, mGluR antagonists, and NOS inhibitor on spreading acidification. $A$, Change in fluorescence as a function of time for series obtained in normal Ringer's solution, in normal Ringer's solution containing the blockers ( $20 \mu \mathrm{M}$ CNQX, 2 mM MCPG, and $1 \mathrm{mM}$ NLA), and after washout of the blockers. In normal Ringer's solution, spreading acidification was evoked at $40 \mathrm{~Hz}$; after the application of the blockers, spreading acidification was not evoked even at higher frequencies $(50$ and $75 \mathrm{~Hz}$ ) but was again evoked at $40 \mathrm{~Hz}$ after washout of the blockers. Stimulation amplitude and duration were kept constant $(200 \mu \mathrm{A}, 200 \mathrm{msec}, 20 \mathrm{~Hz}$ for $5 \mathrm{sec}$ ). B. Field potential recordings in normal Ringer's solution and after application of the blockers.

all increased the threshold for evoking spreading acidification but individually did not completely prevent spread (Figs. 4-6). Therefore, we evaluated whether blocking glutamate transmission and NOS in combination could eliminate spread. As shown in Figure 7, the combination of CNQX (20 $\mu \mathrm{M})$, MCPG (2 mM), and NLA (1 $\mathrm{mm}$ ) completely blocked spreading acidification regardless of the stimulation parameters (Fig. $7 A$ ). With the presence of these blockers, spread could not be evoked with stimulation frequencies as high as $75 \mathrm{~Hz}$, but spread was evoked again at $40 \mathrm{~Hz}$ after the washout of the blockers. As expected, these blockers result in a complete loss of the postsynaptic negativity with no effect on the parallel fiber volley (Fig. 7B). Similar results were found in three animals.

Last, we investigated whether spreading acidification could be evoked in transgenic mice with a targeted mutation (B6;129SNos $1^{\text {tm1plh }}$ ) disrupting the neuronal nitric oxide synthase gene (Huang et al., 1993). In wild-type mice, surface stimulation evoked spreading acidification identical to that in rats (data not shown). In the NOS-deficient mouse, spreading acidification was evoked by surface stimulation in normal Ringer's solution (Fig. $8 A, C)$. The intensity and propagation speed $(559 \pm 87 \mu \mathrm{m} / \mathrm{sec})$ were similar to the spreading acidification evoked in wild type animals. Spread was evoked in the four NOS-deficient mice evaluated. In the NOS-deficient mice, we also evaluated the effect of NLA in an additional four experiments. After application of 1 mM NLA, surface stimulation evoked spreading acidification; albeit the initiation was delayed, and the slope of spread decreased (Fig. 8B,C). When taken together with the results using the NOS inhibitor and NO donor, the data suggest that NO modulates spreading acidification. Furthermore, because NLA is a general NOS inhibitor, non-neuronal NOS isoforms (Dawson et al., 1998) may play a role in spreading acidification.

Spreading acidification was accompanied by a transient decrease in the excitability of the parallel fibers and their postsynaptic targets (Chen et al., 1999a). In that initial report, we described complete suppression of both the parallel fiber volley and the postsynaptic component. Additional experiments have revealed that the depression in excitability need not be complete, as shown in Figure 9. In this example, as the increased fluorescence spread across the folia, there was a transient reduction in the 


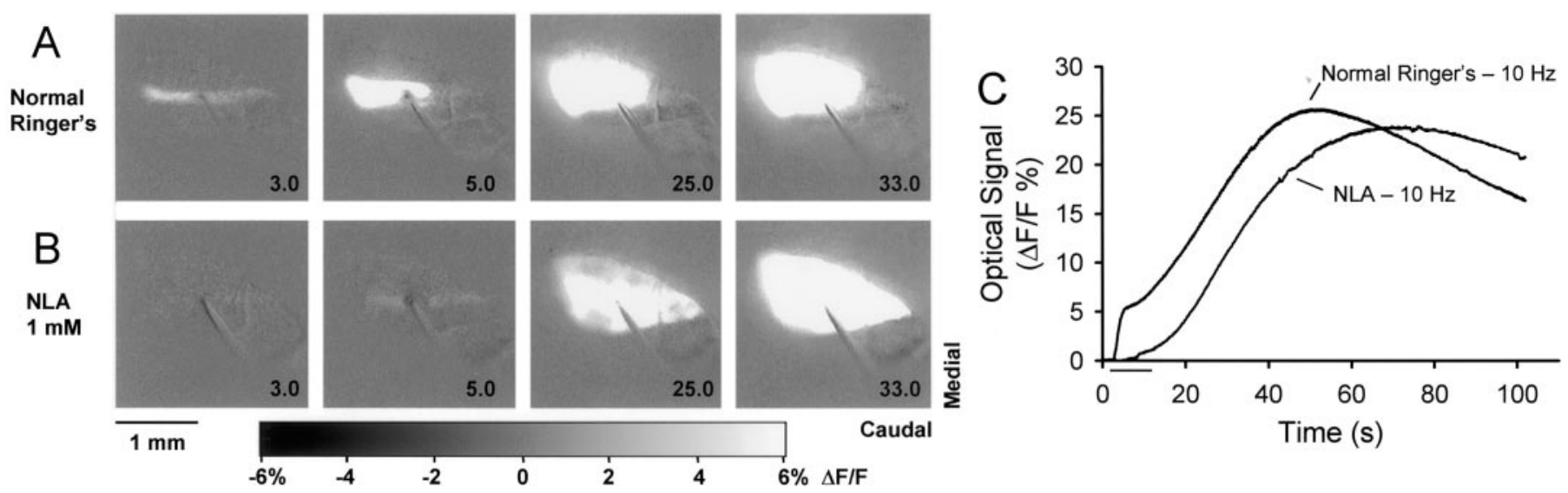

Figure 8. Spreading acidification evoked in neuronal NOS-deficient mice. $A$, Sequence of images showing beam-like optical response to surface stimulation $(100 \mu \mathrm{A}, 10 \mathrm{~Hz}$ for $10 \mathrm{sec})$ in normal Ringer's solution. $B$, Sequence of images showing spread evoked in the presence of NLA (1 mM). $C$, Change in fluorescence as a function of time for each series in $A$ and $B$.

parallel fiber volley $\left(\mathrm{P}_{1}-\mathrm{N}_{1}\right)$ and a complete suppression of the postsynaptic component $\left(\mathrm{N}_{2}\right.$; Fig. $\left.9 A\right)$. The parallel fiber volley was reduced to $\sim 50 \%$ of the control during the initial phase of spreading acidification and the reduction lasted $\sim 20 \mathrm{sec}$ (Fig. 9B). The postsynaptic component $\left(\mathrm{N}_{2}\right)$ was completely suppressed for $\sim 50 \mathrm{sec}$ and recovered to $95 \%$ of baseline at $105 \mathrm{sec}$. The suppression in the postsynaptic response mirrored the increase in fluorescence. However, $\mathrm{P}_{1}-\mathrm{N}_{1}$ completely recovered to normal before the optical signal reached its peak, and $\mathrm{N}_{2}$ almost completely recovered when the optical signal had returned to $50 \%$ of its peak. In four animals, the maximal depression of $\mathrm{P}_{1}-\mathrm{N}_{1}$ averaged $70 \%$, lasted $5 \mathrm{sec}$, and recovered in $25 \mathrm{sec}$. Similarly for $\mathrm{N}_{2}$, the maximal depression averaged $100 \%$, lasted $64 \mathrm{sec}$, and recovered in $112 \mathrm{sec}$. This coupling between spreading acidification and decreased excitability was also observed in the presence of CNQX (Fig. 9C; only $\mathrm{P}_{1}-\mathrm{N}_{1}$ depression recorded), MCPG (Fig. 9D), and NLA (Fig. 9E). The duration of depression was longer in the latter two experiments, reflecting the longer spreading acidification manifested by the longer time course of optical responses.

\section{Role of ATP, purinergic receptors, and furosemide}

It has been shown that ATP acts as the extracellular messenger for $\mathrm{Ca}^{2+}$ waves in mouse cortical astrocyte cultures (Guthrie et al., 1999). Because ATP neurotransmission occurs in the cerebellar cortex, and purinergic receptors are abundant on Purkinje cells (Mateo et al., 1998), the possible involvement of ATP in spreading acidification was of interest. We evaluated the role of purinergic neurotransmission by blocking $\mathrm{P} 2 \mathrm{X}$ purinergic receptors with the antagonist PPADS. As shown in Figure 10A, superfusion with $1 \mathrm{~mm}$ PPADS did not affect the spreading acidification evoked by surface stimulation. In four additional animals, PPADS failed to block or alter the threshold to evoke spreading acidification. A similar result was obtained with suramin, a general antagonist of $\mathrm{P} 2 \mathrm{X}$ and $\mathrm{P} 2 \mathrm{Y}$ receptors (data not shown). We also evaluated the effectiveness of these antagonists by microinjecting adenosine into the molecular layer, which evoked a strong increase in epifluorescence. This increase was blocked by the purinergic antagonists (data not shown). These results suggest that purinergic neurotransmission does not play an essential role, and ATP does not act as an extracellular messenger in the propagation of spreading acidification.
Neuronal activity results in a reduction in the extracellular space and an increase in neuronal and glial volume. This cellular swelling subsequently leads to the increase of light transmittance through tissue (Ransom et al., 1985; Holthoff and Witte, 1996). We have demonstrated previously that neutral red-based epifluorescence signals are primarily modulated by $\mathrm{pH}$ changes and that extracellular space changes do not produce this optical signal (Chen et al., 1998). Still, it was important to determine whether volume changes were the source of the optical signals observed during spreading acidification. Therefore, furosemide, an anion transport inhibitor known to block the extracellular space and cellular volume changes, was used (Ransom et al., 1985; Holthoff and Witte, 1996; Muller and Somjen, 1999). After the application of furosemide (2 $\mathrm{mm}$ ) for $45-60 \mathrm{~min}$, surface stimulation still evoked a spreading acidification (Fig. 10B). We did observe that furosemide (1-2 mM) was toxic to the cerebellar cortex, depressing the field potentials (data not shown) and eliminating all potentials at higher doses. Similar results were obtained in six different animals.

\section{DISCUSSION}

Optical imaging has been used to monitor SD, calcium waves, and related phenomena (Yoon et al., 1996; Newman and Zahs, 1997; Guthrie et al., 1999; Muller and Somjen, 1999). The optical signals in this study were derived from neutral red, a widely used indicator of intracellular pH (Kogure et al., 1980; LaManna, 1987). Although one cannot exclude contributions from other sources to the optical signals, these are probably limited. As discussed previously (Chen et al., 1999a), membrane-associated effects, changes in ion concentrations, and voltage sensitivity are not likely to contribute (Cohen et al., 1974; LaManna, 1987). In the cerebellum, the increase in fluorescence primarily reflects neuronal intracellular acidification (Chen et al., 1998). Our initial report showed that volume changes alone did not produce these epifluorescent optical signals (Chen et al., 1998). When coupled with the present results using furosemide, this suggests that cellular swelling associated with neuronal activity is not the source of the optical signals observed during spreading acidification. However, the electrophysiological and pharmacological results reveal a complex set of events underlying spreading acidification and depression. 


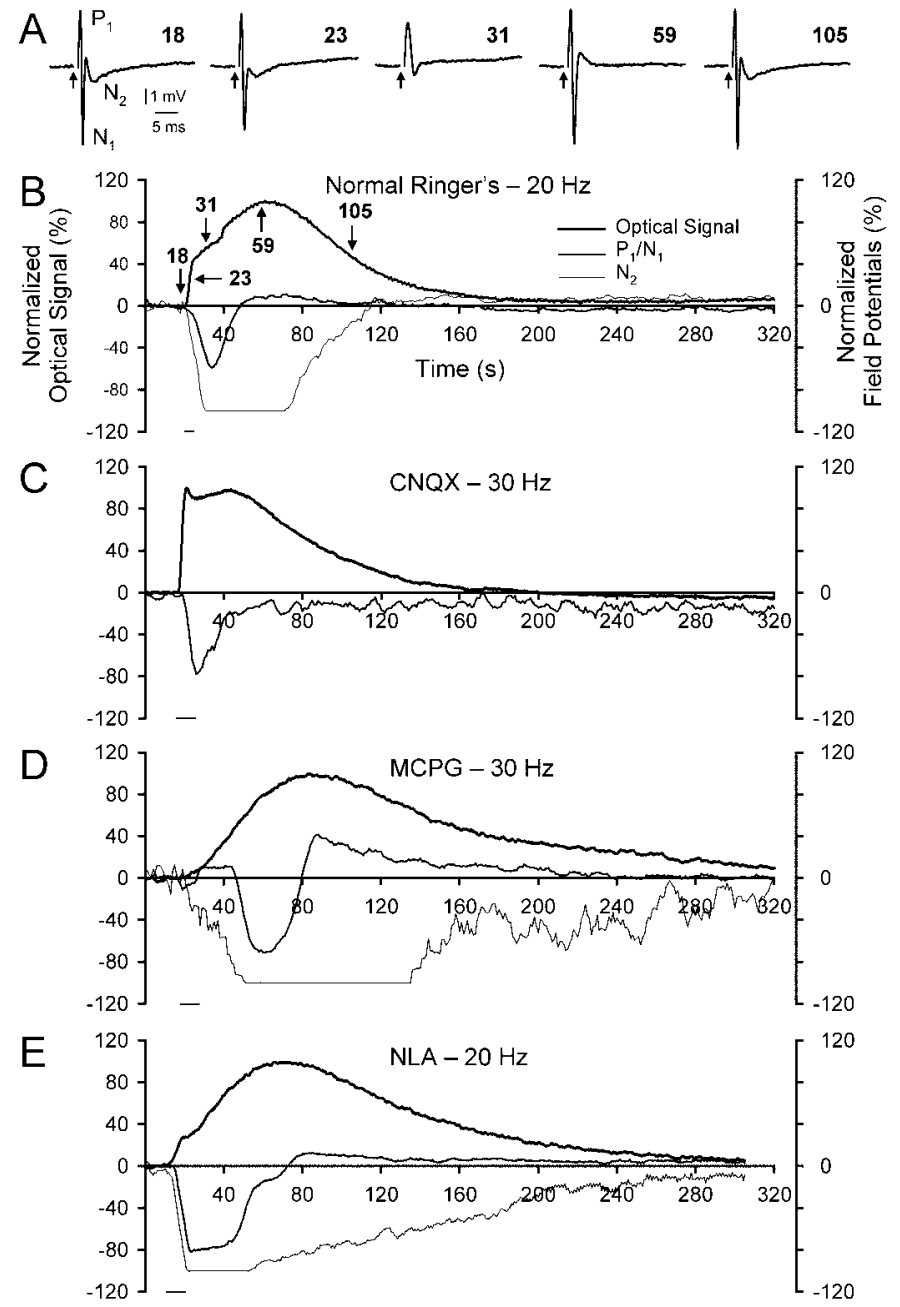

Figure 9. Relationship between the optical response and neuronal excitability. In this experiment, the optical response evoked by the first stimulation electrode and field potentials evoked by the second stimulation electrode were simultaneously recorded, as detailed in Materials and Methods. $A$, Field potentials at selected times (top right corner, in seconds) during spreading acidification. $B$, Normalized optical signal $(\Delta F / F)$ in a $10 \times 10$ pixel region centered at the tip of the recording electrode and $\mathrm{P}_{1}-\mathrm{N}_{1}$ (parallel fiber volley) and $\mathrm{N}_{2}$ (postsynaptic response) as a function of time. The times of field potentials in $A$ are indicated on the plot of the optical signal. $C-E$, same layout as in $B$, but the responses were obtained

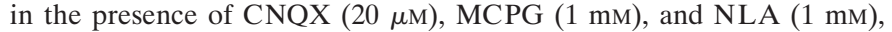
respectively. Note that there is no $\mathrm{N}_{2}$ component in $C$, because the postsynaptic response is completely blocked by CNQX.

\section{Differences with classic spreading depression}

Our original study documented several differences between spreading acidification and depression and classic SD (Chen et al., 1999a). The present study revealed three additional differences. First, activation of NMDA glutamate receptors are critical for evoking SD in the cerebral cortex, whereas non-NMDA receptors are not (Gorelova et al., 1987; Lauritzen and Hansen, 1992). The converse was found for spreading acidification in the cerebellum. Blocking NMDA receptors had no effect, whereas blocking AMPA receptors with CNQX raised the threshold for spreading acidification. Second, the accompanying depression of neuronal activity need not be complete and can be brief, lasting 1-2 min. In $\mathrm{SD}$, the depression is more prolonged and complete (Kraig and Nicholson, 1978; Lauritzen and Nicholson, 1988). Third, some variants of SD can be evoked in $0 \mathrm{Ca}^{2+}$ (Basarsky et al., 1998;
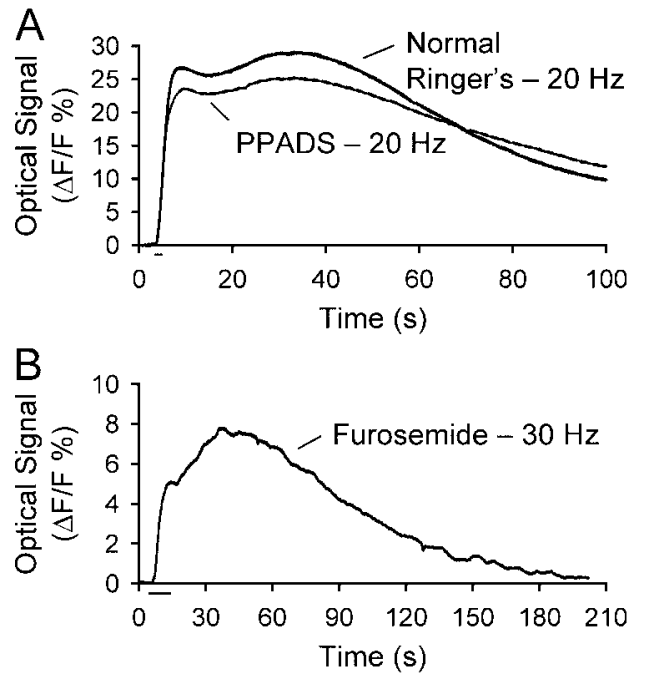

Figure 10. Effect of PPADS and furosemide on spreading acidification. $A$, Change in fluorescence as a function of time for series in normal Ringer's solution and in normal Ringer's solution containing $1 \mathrm{~mm}$ PPADS. Surface stimulation: $200 \mu \mathrm{A}, 20 \mathrm{~Hz}$ for $2 \mathrm{sec}$. B, After topical application of $1 \mathrm{~mm}$ furosemide for $45 \mathrm{~min}$, spreading acidification could still be evoked by surface stimulation $(300 \mu \mathrm{A}, 30 \mathrm{~Hz}$ for $10 \mathrm{sec})$.

Bahar et al., 2000), and spreading acidification cannot. Therefore, spreading acidification and SD differ both phenomenologically and mechanistically.

\section{Presynaptic and postsynaptic contributions}

Activation of parallel fibers alone did not evoke spreading acidification, as demonstrated by the nominally $\mathrm{Ca}^{2+}$-free experiments. This finding suggests that spreading acidification is dependent on activation of the postsynaptic targets of the parallel fibers: Purkinje cells and interneurons. Consistent with this observation is that blocking AMPA receptors, mGluRs, or both raised the threshold for evoking spreading acidification. The latter class of receptors not only increases intracellular $\mathrm{Ca}^{2+}$ but also produces significant excitatory postsynaptic currents when activated at high frequencies (Finch and Augustine, 1998; Takechi et al., 1998). Also, NOS blockers raised the threshold for spreading acidification, and the primary target of NO is the guanyl cyclase in Purkinje cells (Ariano et al., 1982; Boxall and Garthwaite, 1996). Blocking $\mathrm{GABA}_{\mathrm{A}}$ and $\mathrm{GABA}_{\mathrm{B}}$ receptors lowered the threshold for spreading acidification, and the primary target of these inhibitory networks is the Purkinje cell. Therefore, spreading acidification is dependent on the activation of postsynaptic structures, including Purkinje cells.

However, the presynaptic elements contribute to spreading acidification. First, blocking conduction along the parallel fibers with TTX prevented spread. Second, the geometry of the activated parallel fibers and cerebellar cortical circuitry defines the spatial structure of spreading acidification. As shown in Figure 1, spreading acidification is initiated nearly simultaneously along the parallel fiber beam evoked by surface stimulation (Chen et al., 1999a). Therefore, initiation of spreading acidification is not limited to the site of stimulation but occurs along the entire length of the activated parallel fibers.

In addition to its postsynaptic actions, high-frequency stimulation of parallel fibers evokes presynaptic mechanisms that could contribute to spreading acidification. NO release from parallel fibers has a marked frequency dependence, and high-frequency 
stimulation potentiates the release of NO (Shibuki and Kimura, 1997; Kimura et al., 1998). High-frequency stimulation of parallel fibers also results in long-term potentiation of glutamate release (Salin et al., 1996). These effects are consistent with the observation that high-frequency stimulation was effective in evoking spreading acidification and argue for an important role for the parallel fibers.

Therefore, spreading acidification in the cerebellar cortex is a multifactorial process involving glutamate neurotransmission and modulated by NO. Blocking or interfering with these elements in isolation did not prevent spreading acidification but only increased the threshold. However, AMPA and mGluR antagonists and NOS inhibitors in combination completely blocked spreading acidification. It remains to be determined whether these factors converge on a common element or signaling pathway. The removal of extracellular $\mathrm{Ca}^{2+}$ prevented spread. However, the role of $\mathrm{Ca}^{2+}$ is difficult to pinpoint, because increased intracellular $\mathrm{Ca}^{2+}$ is involved in a multitude of signal pathways and cellular processes.

The increased acidification may be attributable to several factors, including (1) increased intracellular $\mathrm{Ca}^{2+}$ and the associated release of $\mathrm{H}^{+}$from internal storage sites (Paalasmaa et al., 1994), (2) glutamate-mediated $\mathrm{H}^{+}$influx (Chen and Chesler, 1992), (3) GABA channel-mediated $\mathrm{HCO}^{-}$efflux (Kaila et al., 1990), and (4) metabolic production of $\mathrm{CO}_{2}$ and lactic acid (Siesjo and Wieloch, 1985). The first two possibilities are consistent with the combined effects of nominally $\mathrm{Ca}^{2+}$-free Ringer's solution and glutamate receptor antagonists. Although the optical signal is argued to reflect intracellular $\mathrm{pH}$ changes, this does not imply that changes in extracellular $\mathrm{pH}$ are not occurring. The well documented coupling between intracellular and extracellular $\mathrm{pH}$ (Chesler, 1990) would predict that extracellular shifts in $\mathrm{pH}$ accompany spreading acidification.

Depression of the cerebellar cortical excitability was found to accompany spreading depression in the presence of AMPA and mGluR antagonists and NOS inhibitors. Therefore, the depression and acidification are highly coupled. The acidification could also contribute to the depression, because a decrease in $\mathrm{pH}$ depresses voltage-gated sodium channel conductance (Tombaugh and Somjen, 1996) and attenuates glutamate receptor channel conductance (Traynelis and Gull-Candy, 1991). Other potential factors are an increase in intracellular $\mathrm{Ca}^{2+}$ and $\mathrm{NO}$ production. Increases in intracellular $\mathrm{Ca}^{2+}$ can induce several cascades that lead to depression of AMPA receptors (for review, see Linden, 1994). NO elevates the endogenous level of cGMP, inhibiting presynaptic $\mathrm{Ca}^{2+}$ currents and neurotransmitter release (Boulton et al., 1994). Therefore, several mechanisms could underlie the presynaptic and postsynaptic depression.

\section{Postulated mechanism of propagation and significance}

A major question is how spreading acidification propagates from cell to cell at these relatively high speeds. Calcium waves and SD in the retina (Martins-Ferreira et al., 2000) as well as SD in the cerebral cortex (Aitken et al., 1998) propagate via glial gap junctions. An extracellular messenger, ATP, has been implicated in the spread of calcium waves in cultures of cortical astrocytes (Guthrie et al., 1999). These events are rather slow and rely on passive diffusion, although $\mathrm{Ca}^{2+}$ waves that precede classic spreading depression propagate at $>100 \mu \mathrm{m} / \mathrm{sec}$ (Kunkler and Kraig, 1998). Furthermore, both calcium waves (Newman and Zahs, 1997; Guthrie et al., 1999) and SD, including SD in the cerebellar cortex, propagate radially from the site of initiation (Chen et al., 1999a). In contrast to $\mathrm{SD}$, spreading acidification propagates at relatively high speed and spreads orthogonally to the activated parallel fibers. Therefore, we postulate that spreading acidification involves a regenerative, i.e., nonpassive, process that uses the underlying parasagittal aspects of cerebellar architecture such as the basket cell axons (Eccles et al., 1967; Ito, 1984).

Of interest is whether spreading acidification in the cerebellar cortex involves an extracellular and intercellular messenger. One candidate evaluated, ATP, is highly unlikely, because the threshold for spreading acidification is not increased by purinergic receptor blockers. The second candidate evaluated, NO, is produced by activation of parallel fibers (Shibuki and Kimura, 1997; Kimura et al., 1998) and has as a target guanyl cyclase in Purkinje cells and in the parallel fibers themselves (Ariano et al., 1982). Blocking NO production raises the threshold for spreading acidification and completely blocks spread in the presence of AMPA and mGluR antagonists. Conversely, an NO donor facilitates spread. However, NO is clearly not the only mechanism, because spreading acidification was evoked in the neuronal NOS-deficient mouse. An important caveat is that other sources of NO, including non-neuronal isoforms of NOS, may still be operative (Dawson et al., 1998). Given this caveat, the role of NO may be its effect on neuronal excitability and not as an intercellular agent.

An important avenue for future investigations is to determine whether glia-glia or neuronal-glia interactions, or both, contribute to spreading acidification. In the cerebellar cortex, glial gap junctions are abundant and strongly coupled, and for Bergmann glia, the coupling is perpendicular to the parallel fibers (Lee et al., 1994; Muller et al., 1996). Repetitive parallel fiber stimulation increases intracellular calcium in Bergmann glia (Grosche et al., 1999; Kulik et al., 1999) that triggers the release of glutamate, which in turn modulates the excitability of neighboring neurons (Parpura et al., 1994; Bezzi et al., 1998; Rouach et al., 2000) and further increases intracellular calcium via both activation of ionotropic glutamate receptors and the inositol-1,4,5-triphosphate pathway (Kirischuk et al., 1999). Therefore, a positive feedback loop exists that could contribute to the propagation of spreading acidification.

The significance of spreading acidification and depression remains undefined. Our working hypothesis is that this represents a pathophysiological phenomenon that could acutely disrupt cerebellar function. An intriguing speculation is that spreading acidification is involved in the episodic ataxias, channelopathies in which the clinical complex includes an acute, transient cerebellar dysfunction (Browne et al., 1994; Ophoff et al., 1996).

\section{REFERENCES}

Aitken PG, Tombaugh GC, Turner DA, Somjen GG (1998) Similar propagation of SD and hypoxic SD-like depolarization in rat hippocampus recorded optically and electrically. J Neurophysiol 80:1514-1521.

Ariano MA, Lewicki JA, Brandwein HJ, Murad F (1982) Immunohistochemical localization of guanylate cyclase within neurons of rat brain. Proc Natl Acad Sci USA 79:1316-1320.

Bahar S, Fayuk D, Somjen GG, Aitken PG, Turner DA (2000) Mitochondrial and intrinsic optical signals imaged during hypoxia and spreading depression in rat hippocampal slices. J Neurophysiol 84:311-324.

Basarsky TA, Duffy SN, Andrew RD, MacVicar BA (1998) Imaging spreading depression and associated intracellular calcium waves in brain slices. J Neurosci 18:7189-7199.

Batchelor AM, Madge DJ, Garthwaite J (1994) Synaptic activation of metabotropic glutamate receptors in the parallel fibre-Purkinje cell pathway in rata cerebellar slices. Neuroscience 63:911-915.

Bezzi P, Carmignoto G, Pasti L, Vesce S, Rossi D, Rizzini BL, Pozzan T, Volterra A (1998) Prostaglandins stimulate calcium-dependent glutamate release in astrocytes. Nature 391:281-285.

Boulton CL, Irving AJ, Southam E, Potier B, Garthwaite J, Collingridge GL (1994) The nitric oxide-cyclic GMP pathway and synaptic depression in rat hippocampal slices. Eur J Neurosci 6:1528-1535.

Boxall AR, Garthwaite J (1996) Long-term depression in rat cerebellum 
requires both NO synthase and NO-sensitive guanylyl cyclase. Eur J Neurosci 8:2209-2212.

Browne DL, Gancher ST, Nutt JG, Brunt ER, Smith EA, Kramer P, Litt M (1994) Episodic ataxia/myokymia syndrome is associated with point mutations in the human potassium channel gene, KCNA1. Nat Genet 8:136-140.

Chen G, Hanson CL, Ebner TJ (1996) Functional parasagittal compartments in the rat cerebellar cortex: an in vivo optical imaging study using neutral red. J Neurophysiol 76:4169-4174.

Chen G, Hanson CL, Ebner TJ (1998) Optical responses evoked by cerebellar surface stimulation in vivo using neutral red. Neuroscience 84:645-668.

Chen G, Hanson CL, Dunbar RL, Ebner TJ (1999a) Novel form of spreading acidification and depression in the cerebellar cortex demonstrated by neutral red optical imaging. J Neurophysiol 81:1992-1998.

Chen G, Dunbar RL, Ebner TJ (1999b) Spreading acidification and depression in the rat cerebellar cortex is mediated by metabotropic glutamate receptor and nitric oxide. Soc Neurosci Abstr 25:1406.

Chen JCT, Chesler M (1992) Modulation of extracellular $\mathrm{pH}$ by glutamine and GABA in rat hippocampal slices. J Neurophysiol 67:29-36.

Chesler M (1990) The regulation and modulation of $\mathrm{pH}$ in the nervous system. Prog Neurobiol 34:401-427.

Cohen LB, Salzberg BM, Davila HV, Ross WN, Landowne D, Waggoner AS, Wang CH (1974) Changes in axon fluorescence during activity: molecular probes of membrane potential. J Membr Biol 19:1-36.

Cornell-Bell AH, Finkbeiner SM, Cooper MS (1990) Glutamate induces calcium waves in cultured astrocytes: long-range glial signaling. Science 247:470-473

Dawson TM, Sasaki M, Gonzalez-Zulueta M, Dawson VL (1998) Regulation of neuronal nitric oxide synthase and identification novel nitric oxide signaling pathways. Prog Brain Res 118:3-11.

Eccles JC, Ito M, Szentagothai J (1967) The cerebellum as a neuronal machine. Berlin: Springer.

Farrant M, Cull-Candy SG (1991) Excitatory amino acid receptorchannels in Purkinje cells in thin cerebellar slices. Proc R Soc Lond B Biol Sci 244:179-184.

Finch EA, Augustine GJ (1998) Local calcium signalling by inositol1,4,5-trisphosphate in Purkinje cell dendrites. Nature 396:753-756.

Gorelova NA, Koroleva VI, Amemori T, Pavlik V, Bures J (1987) Ketamine blockade of cortical spreading depression in rats. Electroencephalogr Clin Neurophysiol 66:440-447.

Grosche J, Matyash V, Moller T, Verkhratsky A, Reichenbach A, Kettenmann H (1999) Microdomains for neuron-glia interaction: parallel fiber signaling to Bergmann glial cells. Nat Neurosci 2:139-143.

Guthrie PB, Knappenberger J, Segal M, Bennett MVL, Charles AC, Kater SB (1999) ATP released from astrocytes mediates glial calcium waves. J Neurosci 19:520-528.

Hanson CL, Chen G, Ebner TJ (2000) Role of climbing fibers in determining the spatial patterns of activation in the cerebellar cortex to peripheral stimulation: an optical imaging study. Neuroscience 96:317-331

Holthoff K, Witte W (1996) Intrinsic optical signals in rat neocortical slices measured with near-infrared dark-field microscope reveal changes in extracellular space. J Neurosci 16:2740-2749.

Huang PL, Dawson TM, Bredt DS, Snyder SH, Fishman MC (1993) Targeted disruption of the neuronal nitric oxide synthase gene. Cell 75:1273-1286.

Iadecola C, Li J, Ebner TJ, Xu X (1995) Nitric oxide contributes to functional hyperemia in cerebellar cortex. Am J Physiol 268:R1153-R1162.

Ito M (1984) The cerebellum and neural control. New York: Raven.

Kaila K, Saarikoski J, Voipio J (1990) Mechanism of action of GABA on intracellular $\mathrm{pH}$ and on surface $\mathrm{pH}$ in crayfish muscle fibers. J Physiol (Lond) 427:241-260.

Kimura S, Uchiyama S, Takahashi HE, Shibuki K (1998) cAMPdependent long-term potentiation of nitric oxide release from cerebellar parallel fibers in rats. J Neurosci 18:8551-8558.

Kirischuk S, Kirchhoff F, Matyash V, Kettenmann H, Verkhratsky A (1999) Glutamate-triggered calcium signalling in mouse Bergmann glial cells in situ: role of inositol-1,4,5-trisphosphate-mediated intracellular calcium release. Neuroscience 92:1051-1059.

Kogure K, Alonso OF, Martinez E (1980) A topographic measurement of brain pH. Brain Res 195:95-109.

Kraig RP, Nicholson C (1978) Extracellular ionic variations during spreading depression. Neuroscience 3:1045-1059.

Kulik A, Haentzsch A, Luckermann M, Reichelt W, Ballanyi K (1999) Neuron-glia signaling via alpha (1) adrenoceptor-mediated $\mathrm{Ca}^{2+}$ release in Bergmann glial cells in situ. J Neurosci 19:8401-8408.

Kunkler PE, Kraig RP (1998) Calcium waves precede electrophysiological changes of spreading depression in hippocampal organ cultures. J Neurosci 18:3416-3425.

LaManna JC (1987) Intracellular $\mathrm{pH}$ determination by absorption spectrophotometry of neutral red. Metab Brain Dis 2:167-182.

Lang EJ (2001) Organization of olivocerebellar activity in the absence of excitatory glutamatergic input. J Neurosci 21:1663-1675.
Largo C, Tombaugh GC, Aitken PG, Herreras O, Somjen GG (1997) Heptanol but not fluoroacetate prevents the propagation of spreading depression in rat hippocampal slices. J Neurophysiol 77:9-16.

Lauritzen M, Hansen AJ (1992) The effect of glutamate receptor blockade on anoxic depolarization and cortical spreading depression. J Cereb Blood Flow Metab 12:223-229.

Lauritzen M, Nicholson C (1988) The pathophysiology of classical migraine. In: headache: problems in diagnosis management (Hopkins A, ed), pp 79-109. London: MPN.

Leao AAP (1944) Spreading depression of activity in the cerebral cortex. J Neurophysiol 7:359-390.

Lee SH, Kim WT, Cornell-Bell AH, Sontheimer H (1994) Astrocytes exhibit regional specificity in gap-junction coupling. Glia 11:315-325.

Linden DJ (1994) Long-term synaptic depression in the mammalian brain. Neuron 12:457-472.

Martin LJ, Blackstone CD, Huganir RL, Price DL (1992) Cellular localization of a metabotropic glutamate receptor in rat brain. Neuron 9:259-270.

Martins-Ferreira H, Nedergaard M, Nicholson C (2000) Perspectives on spreading depression. Brain Res Brain Res Rev 32:215-234.

Mateo J, Garcia-Lecea M, Miras-Portugal MT, Castro E (1998) $\mathrm{Ca}^{2+}$ signals mediated by P2X-type purinoceptors in cultured cerebellar Purkinje cells. J Neurosci 18:1704-1712.

Mateos JM, Azkue J, Sarria R, Kuhn R, Grandes P, Knopfel T (1998) Localization of the mGlu4a metabotropic glutamate receptor in rat cerebellar cortex. Histochem Cell Biol 109:135-139.

Muller M, Somjen GG (1999) Intrinsic optical signals in rat hippocampal slices during hypoxia-induced spreading depression-like depolarization. J Neurophysiol 82:1818-1831.

Muller T, Moller T, Neuhaus J, Kettenmann H (1996) Electrical coupling among Bergmann glial cells and its modulation by glutamate receptor activation. Glia 17:274-284.

Newman EA, Zahs KR (1997) Calcium waves in retinal glial cells. Science 275:844-847.

Nicholson C, Kraig RP (1975) Chloride and potassium changes measured during spreading depression in catfish cerebellum. Brain Res 96:384-389.

Nicholson C, ten Bruggencate G, Stockle H, Steinberg R (1978) Calcium and potassium changes in extracellular microenvironment of cat cerebellar cortex. J Neurophysiol 41:1026-1039.

Ochs S (1962) The nature of spreading depression in neural networks. Int Rev Neurobiol 4:1-69.

Ophoff RA, Terwindt GM, Vergouwe MN, van Eijk R, Oefner PJ Hoffman SMG, Lamerdin JE, Mohrenweiser HW, Bulman DE, Ferrar M, Haan J, Lindhout D, van Ommen GB, Hofker MH, Ferrari MD, Frants RR (1996) Familial hemiplegic migraine and episodic ataxia type- 2 are caused by mutations in the $\mathrm{Ca}^{2+}$ channel gene CACNL1A4 Cell 87:543-552.

Paalasmaa P, Taira T, Voipio J, Kaila K (1994) Extracellular alkaline transients mediated by glutamate receptors in the rat hippocampal slice are not due to a proton conductance. J Neurophysiol 72:2031-2033.

Parpura V, Basarsky TA, Liu F, Jeftinija K, Jeftinija S, Haydon PG (1994) Glutamate-mediated astrocyte-neuron signalling. Nature 369:744-747

Ransom BR, Yamate CL, Connors BW (1985) Activity-dependent shrinkage of extracellular space in rat optic nerve: a development study. J Neurosci 5:532-535.

Rouach N, Glowinski J, Giaume C (2000) Activity-dependent neuronal control of gap-junctional communication in astrocytes. J Cell Biol 149:1513-1526.

Salin PA, Malenka RC, Nicoll RA (1996) Cyclic AMP mediates a presynaptic form of LTP at cerebellar parallel fiber synapses. Neuron $16: 797-803$

Shibuki K, Kimura S (1997) Dynamic properties of nitric oxide release from parallel fibres in rat cerebellar slices. J Physiol (Lond) 498:443-452.

Siesjo BK, Wieloch T (1985) Cerebral metabolism in ischaemia: neurochemical basis for therapy. Br J Anaesth 57:47-62.

Somjen GG, Aitken PG, Czeh GL, Herreras O, Jing J, Young JN (1992) Mechanism of spreading depression: a review of recent findings and a hypothesis. Can J Physiol Pharmacol [Suppl] 70:S248-S254.

Takechi H, Eilers J, Konnerth A (1998) A new class of synaptic response involving calcium release in dendritic spines. Nature 396:757-760.

Tobiasz C, Nicholson C (1982) Tetrodotoxin resistant propagation and extracellular sodium changes during spreading depression in rat cerebellum. Brain Res 241:329-333.

Tombaugh GC, Somjen GG (1996) Effects of extracellular pH on voltage-gated $\mathrm{Na}^{+}, \mathrm{K}^{+}$, and $\mathrm{Ca}^{2+}$ currents in isolated rat CA1 neurons. J Physiol (Lond) 493:719-732.

Traynelis SF, Gull-Candy SG (1991) Pharmacological properties and $\mathrm{H}^{+}$sensitivity of excitatory amino acid receptor channels in rat cerebellar granule neurons. J Physiol (Lond) 433:727-763.

Yoon RS, Tsang PW, Lenz FA, Kwan HC (1996) Characterization of cortical spreading depression by imaging of intrinsic optical signals. NeuroReport 7:2671-2674. 